\title{
TESES E DISSERTAÇÕES DE MESTRADO DEFENDIDAS
}

\author{
(março a agosto de 2001)
}

\section{Teses de Doutorado}

\section{$\checkmark$ o Vale do Ribeira tem jeito. o ecoturismo como alternativa de inclusáo das comunidades}

\section{Devancir Romão}

O objetivo deste trabalho é contribuir para o aprofundamento de um processo que resulta na busca de alternativas de desenvolvimento adequadas ao Vale do Ribeira para que possam garantir a efetiva inclusão das camadas mais pobres da população tanto nas decisōes quanto nos frutos do crescimento e da renda geradas por esse desenvolvimento. Não se tra- ta, portanto, de um trabalho de reflexão teórica sobre modelos de desenvolvimento regional, nem sobre modalidades de atividades turísticas ante o ecoturismo em regiōes economicamente deprimidas. Este pretende ser, sim, um trabalho aplicado, uma reflexão sobre a Agenda de Ecoturismo para o Vale do Ribeira como instrumento de democratização do planejamento regional e de aglutinaçāo das necessidades, anseios e propostas de diferentes atores locais, regionais e estaduais.

Palavras-chave: Vale do Ribeira; comunidades rurais; ecoturismo; políticas públicas; desenvolvimento regional.

\section{T Gestão Municipal e Conservação da Natureza: a bacia hidrográfica do Ribeirão das Anhumas - Campinas/SP}

\section{Marisa Teresinha M. Frischenbruder}

Este trabalho situa-se no campo das discussōes sobre proposiçōes e práticas de planejamento e gestão municipal brasileiras, analisando-se particularmente questōes relativas a condiçōes ambientais e Conservação da Natureza. Tem como centro da análise o processo de implementação de política ambiental, na sua dimensão territorial, realizado no município de Campinas/SP no período 1993/96 e, particularmente, em 1996, quando grande parte da concepção de política de ordenamento municipal tinha já sido concretizada em leis, regulamentos e rotinas de trabalho no Departamento de Meio Ambiente, da Secretaria Municipal de Planejamento e Meio Ambiente, representando o conjunto mais acabado dessa concepção de política. O estudo foi realizado para uma sub-bacia hidrográfica do município, a do Ribeirão das Anhumas, contribuinte do rio Atibaia, situada na porçāo centro-norte/ noroeste de Campinas. Neste trabalho foi dada ênfase aos aspectos relacionados à Conservação da Natureza em áreas intensamente ocupadas urbanas e rurais - e consideradas algumas estratégias que podem ser desenvolvidas pelo Poder Público Municipal. Para essa análise, além do exame dos documentos relativos à política e do 
traçado do percurso realizado entre as concepçóes e a sua concretizarão em práticas, técnicas e ações para implementaçāo, foi construído um modelo cartográfico simplificado do território, procurando caracterizar a Paisagem sob gestáo pública e aspectos importantes da evolução histó- rica de ocupação da regiāo. Foram identificados analogias entre os modelos trabalhados e processos de evolução de modelos, quando estes são utilizados como instrumentos de conhecimento e ação sobre a realidade e modificados, conforme esse processo evolui.

\section{T A qualidade da água de Santa Marial RS: uma análise ambiental das sub-bacias hidrográficas dos rios Ibicuí Mirim e Vacacai Mirim}

\section{Bernardo Sayão Penna e Souza}

Foi realizado um estudo do espaço geográfico, procurando correlacionar os efeitos das açōes que a sociedade executa sobre a superfície terrestre com o seu reflexo na composiçăo da água superficial. Para tanto, tomou-se como área de estudo, as duas sub-bacias hidrográficas que servem de área de captação da água que abastece os dois principais reservatórios que compõem o sistema de abastecimento da água destinada ao consumo pela populaçāo da cidade de Santa Maria, no Rio Grande do Sul, as quais caracterizam-se por serem significativamente diferentes entre si, tanto em suas características físicas, quanto no aspecto da ocupação e uso de sua superfície por parte da população. Caracterizaramse ecologicamente os sistemas ambientais por meio de uma análise integrada das paisagens de cada uma das sub-bacias, sob a perspectiva estruturalista da Ecologia da Paisagem, entendendo- se a natureza como um todo funcional. Foram considerados como aspectos físicos das subbacias: a cobertura vegetal original/remanescente, o clima, a hidrografia, a geologia, os solos e a geomorfologia; e como aspectos humanos: os tipos de uso atualmente aplicados à Terra nos referidos sistemas ambientais. A caracterizaçāo da água natural dos reservatórios foi realizada por determinação de suas características físicas ou estéticas: $\mathrm{pH}$, cor e turbidez; químicas: condutividade elétrica, sólidos sedimentáveis, sólidos totais dissolvidos, dureza total, demanda química de oxigênio, e teores de cloretos, fluoretos, ferro, manganês, cálcio e magnésio; e bacteriológicas: presença de bactérias do grupo coliformes fecais. Como resultados, considerase que a análise das sub-bacias através da Ecologia da Paisagem, sob o paradigma geossistêmico caracterizou eficientemente as condiçōes ecológicas dos dois sistemas ambientais, e que os parâmetros de qualidade das águas apresentaram forte correlação com o tipo de uso aplicado à terra, respeitadas as diferenças físicas dos espaços analisados.

Palavras-chave: Geoecologia, análise ambiental integrada, ecologia da paisagem, geossistemas, qualidade da água, geomorfologia.

\section{Timites do consenso: territórios polissêmicos na Mata Atlântica e a gestão ambiental participativa}

Carmem Lúcia Rodrigues
A perspectiva discursiva nos ensina que nāo há uma verdade única, objetiva e monolítica a respeito da relaçáo cultura/espaço. Até hoje, poucas são as informaçōes divulgadas a respeito de saberes e ideais de uso do espaço de povos 
tradicionais que vivem nas Unidades de Conservação (UCs) da Mata Atlântica - como é o caso dos caiçaras, quilombolas e de determinadas etnias indígenas. Esta lacuna leva-me a questionar o sentido do "caráter participativo" atribuído aos planos de manejo e de gestāo ambiental conduzidos pela Secretaria do Meio Ambiente do Estado de São Paulo, no âmbito do Projeto de Preservação da Mata Atlântica (PPMA). Até hoje, é o imaginário de um grupo específico de profissionais - a maioria formada nas ciências naturais - que tem se expressado e, ao mesmo tempo, orientado a grande maioria dos programas de proteção da natureza no Brasil, desconsiderando-se saberes e práticas locais. Contudo, será que não haveria outro caminho possível?
A compreensāo das relaçōes dos moradores locais com o meio onde vivem - seu lugar - é fundamental para apontar pressupostos de um ordenamento territorial, efetivamente participativo. O diagnóstico e o planejamento ambiental não devem se restringir ao ponto de vista meramente instrumental. Assim, este trabalho ressalta a importância de se considerar na elaboração de planos de gestāo ambiental das áreas protegidas o conhecimento tradicional, além de levar em conta, nesse processo coletivo, aspectos que fazem parte de uma dimensão mais subjetiva do ser humano.

Palavras-chave: Mata Atlântica, conservaçāo ambiental, territorialidade e identidade, ordenamento territorial participativo, ONGs.

\section{Tr Telecomunicaçóes, informática e informaçáo e a remodelaçáo do território brasileiro}

\section{Cilene Gomes}

Nessa busca de entender a sociedade de nosso tempo, espaço e técnica são os principais referenciais de método adotados. Em todos os âmbitos da atividade humana, a evolução técnica tem engendrado mudanças profundas $e$ inéditas. As comunicaçōes à distância constituem um dos universos onde essas transformaçōes ocorrem de forma surpreendente e acelerada, e a informação torna-se nāo somente o princípio ativo da revoluçāo científico-técnica $e$ da produção da vida econômica e social em todo o seu espectro, como também uma das grandes questōes da atualidade.

Em vista de reafirmar o enfoque da geografia como filosofia das técnicas (Milton Santos) e reconstituir a remodelaçāo do território brasileiro nos últimos decênios, os sistemas técnicos de telecomunicaçóes, informática e informação foram tomados como o objeto central da pesquisa. Dado esse recorte, buscamos proceder a uma releitura da história recente do país com o objetivo de ressaltar alguns momentos decisivos do processo de governo que teriam demarcado o desenvolvimento geral $e$ as sucessivas implantaçōes desses sistemas técnicos, as suas localizaçōes preferenciais, o rearranjo de ordem socioespacial que resulta em meio às distintas regiōes do país, etc.

Nessa reacomodação das hegemonias nacionais aos tempos e modos produtivos da globalizaçăo, o processo de informatizaçăo da sociedade ascende, com força, como um dos movimentos de repercussōes mais notáveis. As indústrias e as unidades provedoras de serviços e informaçōes crescem e se diversificam, concentrando-se nos espaços mais qualificados ou deslocalizando-se a pontos estratégicos do território; recriando as formas do uso social e o contexto das atividades econômicas e sociais; induzindo ao consumo, acirrando desigualdades, suscitando questōes fundamentais, etc.

Baseados em diversos inventários de natureza factual, um novo universo tende a se entreabrir às nossas reflexōes, a propósito das 
novas constituições científico-técnicas e informacionais e suas relaçōes, com o permanente processo de remodelação do espaço territorial. Quer consideremos o atual estágio de integração do território brasileiro, quer contemplemos a questão geográfica da diferenciação dos contextos regionais ou locais, os pontos-chave a recobrar - não somente a título de uma conclusão para esse trabalho, mas sobretudo em vista de novos estudos e pesquisas -, apontam ao

\section{Tr Geografia e paisagem: entre o olhar e o pensar}

\section{Cláudio Benito Oliveira Ferraz}

Esta pesquisa estuda o conceito de paisagem, de forma a contribuir para a ampliação do olhar geográfico sobre o espaço. Desde a institucionalização deste saber, na segunda metade do século XIX, que as formas e metodologias adotadas para se olhar o mundo e pensar sobre o mesmo visava, majoritariamente, a possibilidade de controle da porção do território observada e estudada. Sempre foi um olhar que buscava a objetividade, a classificação, a disposiçāo, o rigor e o domínio, portanto, um olhar centralizador e padronizador. Atualmente, perante os avanços tecnológicos e as novas necessidades sociais, esse olhar que se coloca como absoluto, pois visa à verdade única $e$ irrefutável do como se pensar cientificamente o real, vem expressando seus limites, o que cobra um refletir sobre o mesmo, buscando entender sua gênese e suas possibilidades futuras, de forma a melhor contribuir para um conhecimento científico que nāo se sobreponha ao real, mas que possa contribuir para o melhor entendimento deste. problema crucial que supõem as defasagens socioespaciais, aos problemas reais para uma remodelação desejável à sociedade em seu todo, a um processo de conscientizaçáo social e pessoal que se espera poder, gradualmente, conduzir à idealização e construção de um espaço de localizaçōes solidárias, um espaço efetivamente mais humano.

Palavras-chave: Espaço, técnica, informação, informatização, território.
Partindo disso, esta pesquisa identificou a origem desse olhar sobre a paisagem, a partir do longo processo de transformação do mundo feudal para as atuais condições da sociedade capitalista, principalmente no decorrer do Renascimento, período que resgatou as bases da matemática e da geometria grega, dando um sentido mais prático e científico a estas, o que muito contribui para a consolidação de uma determinada forma de se ver o pensar o mundo a partir dessa espacialidade então exercitada, como constatamos nas expressões arquitetônicas e em quadros, por exemplo. Por meio de análise de vários quadros, pintados ao longo dos séculos XVI, XVII, XVII, XIX e XX, vamos exemplificando como esse olhar foi evoluindo, consolidando-se, demonstrando seus limites, assim como ocorreram buscas de superação às suas deficiências, chegando ao momento atual em que a ampliação de formas de representação e leitura dessa espacialidade, a partir da paisagem observada e experimentada, aponta para a geografia desafios e possibilidades de pensar o espaço, a partir da paisagem, resgatando também os necessários aspectos subjetivos e cotidianos, de forma que a vivência dessa espacialidade, produzida socialmente, seja mais bem objetivada e entendida em seus parâmetros lógicos e teóricos 


\section{CT Desmatamento, urbanização do campo e variabilidade climática na Amazônia mato-grossense}

Cleusa Aparecida Gonçalves Pereira Zamparoni

O presente estudo analisa as alteraçōes climáticas ocorridas na Amazônia mato-grossense, derivadas do processo de colonização a partir da década de 1970, tomando como amostragem os municípios de Sinop, Sorriso e Vera, localizados na Bacia do Médio Teles Pires.

No contexto da apropriação, ocupação e transformaçāo do espaço na Amazônia matogrossense, os dados relativos à evoluçāo temporal/espacial do processo de desmatamento da área de estudos, foram mapeados e quantificados, resultando em porcentagens de áreas ocupadas e áreas com vegetação remanescentes.

Os dados resultantes do acréscimo populacional da área de estudo, e o crescente processo de urbanizaçāo do campo na Amazônia mato-grossense foi enfocado à luz das correntes migratórias rural/urbana, derivadas dos processos de modernização da agricultura na regiāo Sul do Brasil.

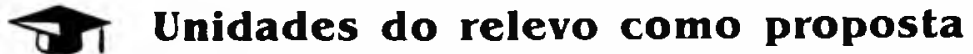 de classificação das paisagens da Bacia do Rio Curu - Estado do Ceará}

Fátima Maria Soares

A presente pesquisa objetiva aplicar os métodos de pesquisa e análise utilizados no estudo integrado da Paisagem, campo do conhecimento geográfico, como área de atuação capaz de romper com a dicotomia Geografia da Natureza e Geografia da Sociedade.

Por meio do estudo integrado da Paisagem, foi possivel ter acesso a diversas áreas do
A análise dos resultados das tendências das variáveis climáticas analisadas no período de 1973 a 1998, subsidiou a verificação de possíveis alteraçōes climáticas, derivadas do processo de ocupação e transformação da área estudada.

Enquanto que no município de Vera, o desmatamento de sua área total foi de $31 \%$; em Sinop foi de $47,08 \%$; em Sorriso chegou a $66 \%$, até o ano de 1997, a partir do processo de ocupação da área, na década de 1970 . O processo de urbanização do campo se manifestou nos três municípios objeto deste estudo, pois a maior parte da população migrante está concentrada nas áreas urbanas.

Ficou evidenciado um acréscimo nas médias anuais das temperaturas do ar, das máximas e mínimas, um decréscimo nos valores das médias anuais das chuvas e acréscimos nos valores das médias anuais da umidade relativa e evaporação.

Concluiu-se que as modificaçōes nas variáveis climáticas possuem relaçōes com o processo de desmatamento e o processo de urbanizaçāo do campo nos municípios de Sinop. Sorriso e Vera, localizados na Amazônia mato-grossense.

conhecimento científico e com a ajuda de técnicas e tecnologias, redimensionar esses conhecimentos fracionados, que são uno e indissociáveis em suas açōes e reaçōes.

Para aplicação do estudo, selecionou-se a Bacia Hidrográfica do Rio Curu, Estado do Ceará, na Regiāo Nordeste brasileira; o critério da escolha, constituiu-se num dos primeiros pontos a ser respeitado pelo método, que consiste a delimitação da área geográfica. As fronteiras naturais vão possibilitar o entendimento no tempo e espaço, de como as transformaçóes de longo e curto período de tempo foram se processando e quais as variáveis que desencadearam tais mudanças. 
A área selecionada terá portanto, uma dimensão escalar, que será ponto de referência. As áreas vão sendo redelimitadas em unidades menores, conforme suas características topográficas, e a cada uma delas vão sendo interconectadas informaçóes referentes a sua geologia, que se vai constituir como suporte delineador das formas, os agentes atmosféricos, como impulsionadores das transformaçōes, o solo e a vegetação, como catalisadores do ambiente natural, e as açōes da sociedade, como agentes ininterruptas de mudanças.

A partir da delimitaçăo da área em unidades menores, foram incorporadas em cada uma delas, novas informaçōes, que foram qua- lificadas, quantificadas e analisadas. Posteriormente, foram atribuídas as variáveis, valores, conforme grau de utilização e de danos ambientais identificados. Todas essas informaçōes possibilitaram testar técnicas de valorização da Paisagem, em que entre os critérios estão dados de caráter objetivo e subjetivo, que requer do pesquisador imparcialidade e caráter científicos para que os resultados obtidos, sejam os mais próximos do real.

O documento tornou-se um laudo técnico e científico para ser utilizado como suporte para projetos tanto de cunho socioeconômico quanto ambiental.

\section{Tा A reinvenção das cidades para um mercado mundial}

\section{Fernanda Ester Sanches Garcia}

O presente trabalho tem como tema as políticas urbanas dos anos 90, particularmente aquelas referentes à promoção das cidades nas escalas local, regional e global. Propóe-se orientar a discussão para a produção de imagens e discursos relacionados com as mudanças nas políticas urbanas de virada de século, sobre a base da cada vez maior centralidade das açōes que perseguem a promoçāo das cidades nas diversas escalas. O objetivo do estudo é explicitar o papel desempenhado pelas políticas de marketing urbano junto aos processos materiais de renovação espacial que dão emergência à cidade-mercadoria e ao mercado mundial de cidades. Na difusāo transescalar das imagens de cidade identifica-se uma dimensão relevante das estratégias de construção de hegemonia do pensamento e açāo sobre as cidades: a dimensão espacial. Mas o estudo mostra que a atual hegemonia do capitalismo global ao mesmo tempo em que induz alinhamentos na esfera econômica e na produção do espaço, atinge em cheio o cerne dos processos de constituição e legitimaçāo de paradigmas. Esta identificação define a orientaçāo metodológica do trabalho que enfatiza a mútua dependência entre materialização e simbolização como relaçāo que constrói as possibilidades históricas de efetivação dos interesses globais e seus agentes na nova espacialidade urbana. A leitura crítica das políticas internacionais de promoção de alguns modelos de cidade e de difusāo transescalar de suas imagens, orientada por meio de planos de análise, comparaçāo e contra-ponto, permitiu, no decorrer do trabalho, chegar a uma síntese. Esta sintese desvenda a emergência de um conjunto estruturado e estruturante de representaçōes que configuram uma cidade-tipo, referência ideológica e prático-estratégica para novos projetos de renovaçāo urbana em diversas cidades do mundo. Efetivamente, o trajeto percorrido nesse estudo permitiu desvendar suficientes indicadores da existência de uma rede global na qual operam fluxos informacionais associados à cidade-tipo, imbricados nos processos constituintes de um mercado global de cidades. 


\section{Ti A bola nas redes e o enredo do lugar: uma geografia do futebol e seu advento no Rio Grande do Sul}

\section{Gilmar Mascarenhas de Jesus}

Ao longo da primeira metade do século $\mathrm{XX}$, o futebol se disseminou completamente pelo território brasileiro, tornando-se ingrediente indelével da tardia integração territorial e um dos mais poderosos elementos definidores da nacionalidade. Tal modalidade esportiva triunfou nas cidades brasileiras com alarde, e não obstante sua evidente expressão espacial, não existe qualquer esboço de uma geografia do futebol no Brasil. Por outro lado, a historiografia do futebol brasileiro ignora os condicionantes da base territorial. No sentido de contribuir na superação inicial destas limitações, almejamos construir e aplicar uma abordagem geográfica para o processo de introdução do futebol no Brasil, enfatizando o peso do lugar e da dinâmica es- pacial, como fatores determinantes da natureza e do ritmo da adoção da inovação.

A introdução do futebol no Brasil está basicamente ligada às conexões territoriais com o Império Britânico. A presença dessas redes (que veiculam a informaçāo "futebol") se define pela natureza da inserção do País na divisāo internacional do trabalho, no bojo da grande expansão capitalista da segunda metade do século XIX. Neste cenário, o Rio Grande do Sul adotou precocemente o futebol e realizou uma difusão de ampla cobertura espacial. Nosso objetivo é verificar até que ponto a configuraçāo territorial e a dinâmica de atuação das redes nela atuantes propiciaram o contato com esta inovação e o êxito particular de sua difusão no Rio Grande do Sul.

Em síntese, pretendemos oferecer ao mesmo tempo um novo olhar para a história do território gaúcho e uma efetiva contribuição à história social do futebol brasileiro, bem como propor uma consistente abordagem geográfica da difusão espacial do esporte mais popular do mundo.

\section{CT Subsidios à discussão de um plano de desenvolvimento sustentável para o Estado de Roraima}

Jaime de Agostinho

Dentro da filosofia que norteia um trabalho de Doutorado, esta tese visa fornecer contribuiçōes efetivas e práticas para a sociedade, subsidiando discussões para a elaboração de um Plano de Desenvolvimento Sustentável para Roraima. Esse plano deve induzir as políticas de desenvolvimento econômico-social baseadas em atitudes concretas de proteção ambiental a sistemas naturais únicos ou frágeis, com mecanismos para sua preservação ou conservação, além de um adequado manejo dos recursos naturais, visando a máxima agregaçăo de valor às matérias primas, diminuindo assim o déficit ambiental e econômico do Estado.
Em função do Estado ainda não ter uma política de governo integrada dentro de uma filosofia de ecodesenvolvimento, este trabalho pretende subsidiar discussōes voltadas para o estabelecimento de estratégia de desenvolvimento que considere o racional aproveitamento dos seus potenciais, com proteçāo ambiental e respeito às populaçōes tradicionais, gerando, conseqüentemente, uma melhor qualidade de vida a seus habitantes. Neste trabalho também são sugeridas alternativas para os tomadores de decisão no Estado, frente ao atual quadro de bloqueio institucional por que passa Roraima, fator que limita drasticamente a utilizaçāo plena de seu espaço físico à maior parte das atividades econômicas tradicionais.

Para a consecução deste trabalho, foram integradas técnicas e metodologias de diversas áreas do conhecimento dentro de uma 
visão geográfica, dando uma análise mais prática e realista da atual situação do Estado de Roraima, contribuindo em paralelo para promover o avanço do conhecimento geográfico da região, já que os poucos levantamentos de caráter global encontram-se defasados ou desarticulados.

\section{Caracterização morfopedológica e suscetibilidade erosiva dos solos de sub- bacias hidrográficas em áreas de expansão urbana de Goiânia, GO}

\section{Luciana Maria Lopes}

Em Goiânia, capital do estado de Goiás, e seus arredores, observa-se um grande contraste entre os terrenos a nordeste e sul da capital, situados, respectivamente, nos vizinhos municípios de Goianápolis e Aparecida de Goiânia. Nessas regiōes foram eleitas, para estudo, duas sub-bacias representativas da fisiografia e do uso/ocupaçāo atuais da terra: a sub-bacia do córrego Carapina, a nordeste, com altitude máxima de $1.010 \mathrm{~m}$, e a sub-bacia do córrego das Lajes, ao sul da capital, a $880 \mathrm{~m}$.

A sub-bacia do córrego Carapina, elaborada sobre as litologias variadas do Complexo Granulítico Anápolis-Itauçu, apresenta diferentes tipos de modelados, e uma grande diversidade de solos. O compartimento de Cimeira $(1.010$ a $980 \mathrm{~m})$, sustentado por paragranulitos, é parte integrante de chapada regional. Aos seus trechos planos, e às vertentes longas suavemente convexiformes das suas bordas, com até $12 \%$ de declividade, associam-se latossolos vermelho escuros distróficos argilosos. No âmbito dos terrenos do compartimento dissecado da borda da chapada (980 a $780 \mathrm{~m})$, sobre as vertentes médias/curtas retilíneas e/ou suavemente convexiformes, com declividades entre 12 a $35 \%$, encontram-se cambissolos eutróficos com Podzólicos subordinados evoluídos de rochas metamórficas ácidas e básicas. O compartimento rebaixado $(780$ a $740 \mathrm{~m})$ é caracterizado por declividades entre 5 a $12 \%$, e presença de la- tossolos roxos distróficos argilosos, derivados de rochas metabásicas.

A sub-bacia do córrego das Lajes situa-se a sul de Aparecida de Goiânia, conurbada ao sul com a capital. Elaborada, em sua maioria, sobre os micaxistos do Grupo Araxá-sul de Goiás, apresenta menor diversidade de modelados e de solos. No compartimento de Cimeira (880 a $820 \mathrm{~m}$ ), sobre as vertentes longas, suavemente convexiformes, com 2 a $12 \%$ de declividade dele característicos, encontram-se latossolos vermelho escuros distróficos de textura média/argilosa dominantes associados a latossolos vermelho escuros/vermelho amarelos, latossolos vermelho amarelos e gleis. Sobre os quartzitos da Serra da Areia encontram-se litólicos, cambissolos e areias quartzosas, todos distróficos.

Para o estudo físico-biótico das bacias procedeu-se à contextualização regional do meio físico por meio da compilaçāo e/ou elaboração de mapas temáticos que orientaram a compartimentaçáo morfopedológica por correlação, em escala de semidetalhe e detalhe. Caminhamentos de campo e tradagens precederam a escolha, nos diversos compartimentos, de locais para descrição e coleta de amostras de perfistipo representativos das unidades de solo existentes nas bacias além do que foram coletadas rochas em sua base ou em afloramentos vizinhos. Através da petrografia das rochas, bem como do estudo morfopedológico em escala de detalhe, e da ênfase na caracterizaçāo macro e micromorfológica, mineralógica, física e química dos solos, compreendeu-se sua gênese e evoluçāo, sua filiação com as diversas litologias $e$ suas suscetibilidades erosivas, o que se revelou particularmente útil como subsídio ao planejamento do uso e ocupação periurbanas da regiāo metropolitana de Goiânia. 
Concluiu-se que: 1) há forte filiação entre os solos $\mathrm{e}$ as litologias nas duas sub-bacias, que foram interpretadas como resultantes de processo morfopedogenético ligado à dissecação ainda em desenvolvimento na sub-bacia do Carapina, e mais evoluído na sub-bacia do Lajes; 2) a suscetibilidade erosiva dos solos na subbacia do Lajes é maior, associada à natureza arenosa fina filiada aos quartzitos, e aos teores de areia fina daqueles derivados dos micaxistos, e menor na sub-bacia do Carapina, associada à natureza argilo-arenosa a argilosa e às macro e microestruturas em blocos ou microagregados, embora o relevo seja mais suave na primeira, e mais movimentado e com presença significativa de Cambissolos na segunda; 3) a textura e a estrutura dos solos revelaram-se como atributos decisivos na avaliação da suscetibilidade erosiva das duas sub-bacias; 4) a sub-bacia do Lajes é a mais vulnerável ao escoamento superficial concentrado (erosão linear ou em sulcos), enquanto a do Carapina é a mais sujeita ao escoamento difuso (erosão laminar).

Os usos e manejos são, portanto, bastante diferentes, recomendando-se controles preventivos próprios a cada uma. A sub-bacia do Carapina poderá continuar destinada ao uso que apresenta, porque adequado. Caso porém, venha um dia a ser urbanizada de modo não planejado, estará sujeita à ocorrência de movimentos de massa. A do Lajes, a continuar como área de expansão urbana, deverá observar atentamente a legislação para loteamentos urbanos, não apresentando riscos de movimentos de massa, a não ser nos eventuais taludes de voçorocas que certamente poderão aparecer.

\section{Tr Território nacional e fronteiras internas: a fragmentação do território brasileiro}

\author{
Márcio Antonio Cataia
}

Este trabalho visa refletir sobre as fronteiras internas e a fragmentação do território brasileiro. A partir da formação e da integração do território, procura-se demonstrar como, no período técnico-científico e informacional, as fron- teiras são manipuladas não só a partir do lugar, mas também por interesses estranhos a ele.

No atual período, a expansão das fronteiras obedece também a uma racionalidade que foge aos interesses do lugar e está atrelada à atuação de empresas que dispōem da totalidade do território à sua ação.

Novos municípios surgem, fragmentando o território, para atender a interesses corporativos, produzindo uma verdadeira alienação dos territórios.

\section{T/ Sertão no plural, da linguagem geográfica ao território da diferença}

Maria de Fátima Ferreira Rodrigues

O tema desta tese é o sertão na história do pensamento social brasileiro. O percurso empreendido, tendo em vista a busca de elementos que possibilitassem a sua elucidação, teve na Geografia, na História e na Literatura Brasileira, seus referenciais. Estes campos do saber sáo visitados por meio das crônicas de viagens, dos relatos dos viajantes, da literatura regionalista e da literatura acadêmica. 
No roteiro de pesquisa delineado ao longo do que se segue, é possível observar que, nos primórdios da colonização, a noção de sertão associou-se a uma forma de nomear lugares ermos e, em geral, longe da costa. Contudo, nas primeiras décadas do século $\mathrm{XX}$, seguindo o viés teórico-naturalista, essa forma de representação ganhou delimitaçāo fisiográfica. A partir de então, predomina na história do pensamento social brasileiro, o uso da noção de sertāo remetendo-a a "sertão nordestino".

\section{Tr Santa Maria de Belém do Grão Pará: Cidade velha do presente no olhar do passado}

\author{
Maria de Jesus B. da Silva
}

Trato neste trabalho compreender a vida social do homem e o como se dá essa relação, na formação, constituição e desenvolvimento do indivíduo, sob o modo de produção capitalista e as relaçōes de reprodução, e como a História irrompe na vida de todo dia desse homem e travado aí o embate a que se propōe: o de realizar no tempo miúdo da vida cotidiana as conquistas fundamentais do gênero humano aquilo que liberta o homem das múltiplas misérias que o fazem pobre de tudo: de condiçōes adequada de vida, de tempo para si, e as relações que se dão no lugar, em face aos poderes constituídos que o privam de agir dignamente,

Nesta perspectiva, busca compreender a realidade por meio de uma abordagem geográfica, relacionada ao espaço enquanto lugar das práticas cotidianas. E como situar essas práticas cotidianas na sociedade moderna, no global, no lugar específico de um homem específico, não querendo dizer que este lugar e este homem sejam exclusivos, eles fazem parte de um contexto maior, contudo os eventos que os atingem têm dinâmicas próprias. Portanto, as transfor-
Com base na literatura que serviu de suporte à composiçáo desta tese é possivel inferir que, na busca de entendimento do encontro entre duas civilizações com ideais, visões de mundo e culturas diversas, encontram-se os elementos que compóem a nossa brasilidade. Brasilidade cujas balizas remetem ao processo de formação territorial do pais e á sua cena cultural, fundamento das distintas formas de representar o sertāo.

Palavras-chave: Geografia, sertāo, brasilidade, representação, cultura. maçōes ocorridas em Belém que afetam a vida das pessoas devem ser consideradas e analisadas como elementos do processo de reprodução das relaçōes sociais de produção, parte de um processo social que ao destruir os antigos modos de vida traz implícitas condiçōes de emergência de um novo modo de vida adaptado às novas determinaçōes existentes. Estas não são apenas econômicas, estende-se ao social, cultural e ao político.

É neste contexto que a redefiniçāo da malha política-administrativa da área de Belém se apresenta como instrumento de análise válido para o entendimento da dinâmica à qual se reporta a intenção deste trabalho.

A pesquisa Santa Maria de Belém do Grāo Pará: a Cidade Velha do presente no olhar do passado surgiu como uma preocupaçāo dos desencontros entre o Estado e a sociedade, nossa preocupaçāo será entender, do ponto de vista geográfico as questōes que permeiam as relaçōes reais do dia-a-dia na cidade e no bairro tendo como ponto de partida no processo de conhecimento e suas manifestaçōes concretas no bairro.

A realidade urbana do bairro da Cidade Velha é um desafio ao planejamento que, nos últimos anos, o conjunto histórico-cultural que perfaz todo o bairro, vem sofrendo intensa descaracterização provocada não somente pelos moradores do bairro, como também por empre- 
sários locais que transformam importantes residências históricas em depósitos comerciais ou com demoliçōes sucessivas para uso de estacionamento.

A Cidade Velha está em transe, este fato aparece de forma pouco transparente nos estudos e projetos de renovação feitos para o bairro. Intencionalmente ou não, parece-nos que estes projetos e estudos ignoram as profundas mutaçōes ocorridas no bairro. As transformaçōes irreversíveis pelas quais passou o bairro apresentam um descompasso com as propostas contidas nos projetos para solucionar seus problemas. Tocam na ponta de Iceberg. Subestimando problemas como: o desmoronamento dos velhos casarōes; as condiçóes de deterioração das edificaçōes do início da fundação da cidade (século XVII). A Cidade Velha vive o transe de um sistema incapaz de suportar suas contradiçōes básicas, onde os interesses do grande capital ditam as regras do sistema e onde as leis do capital definem a natureza da urbanização, fazendo da cidade o seu centro nervoso. Os problemas da Cidade Velha representam o microcosmo de um processo de urbanização que é universal ao capitalismo. Proble- mas semelhantes são vividos em outros bairros e cidades do sistema. A anarquia capitalista é a "camisa de força do planejamento" fazendo com que o capitalismo viva em constante transe. Inviabilizando qualquer prática democrática de urbanismo. O "individualismo" é como a essência daquela anarquia, estará sempre favorecendo as classes dominantes na apropriação do espaço.

Assim, o bairro da Cidade Velha faz emergir as contradiçōes entre o Estado e a sociedade, $o$ individual e o coletivo, o velho e o novo

A preocupação fundamental é entender no contexto da visualização; a cidade como um problema e ao mesmo tempo como um lugar de progresso representativo de uma sociedade como um todo e montar estratégias objetivando a valorização do núcleo inicial do Município de Belém. Fica evidente o princípio de cada um em seu lugar, no tamanho e na forma propostos pelo poder instituído e considerado como competente para ditar normas, uma vez que a intervenção do Estado na sociedade nāo se dá por meio de seus diversos agentes.

Palavras-chave: Espaço, urbano, lugar, cidade, bairro, relaçōes sociais.

\section{$\overparen{T}$ Turismo e excursismo: o qualificativo rural - um estudo das experiências e potencialidades no Norte Velho do Paraná}

\section{Maria del Carmen Matilde Huertas Calvente}

Este estudo enfoca a diversificação contemporânea do turismo, na perspectiva da Geografia, tendo o turismo rural como tema central e como subtemas a sua potencialidade, regulamentaçāo, impactos e perspectivas. Entre as tendências atuais da prática social do turismo está a valorização da rusticidade e de paisagens naturais - as áreas rurais passam. portanto, a ser encaradas também como um território de suporte para as atividades de lazer.
O turismo rural, no caso brasileiro, não possui um conceito já determinado, e na discussão do que é ou deve ser e na inter-relação entre os vários agentes ligados à sua regulamentação algumas possibilidades são vislumbradas: a atividade pode servir para uma modernização que exclui grandes parcelas da populaçāo brasileira, mas também pode ser encarada como uma maneira de incorporação destas pessoas nas transformaçóes que a sociedade necessita. $O$ texto resultante e aqui apresentado foi dividido em cinco partes: a diversificação do turismo enquanto um processo contemporâneo, investigando suas tendências atuais; as diferentes contribuiçōes que servem à compreensāo conceitual do tema principal e um levantamento dos 
problemas e benefícios relatados como possiveis; as diversas açōes que influem no turismo rural, nas mais diversas escalas; os elementos da potencialidade; e um quadro do turismo rural na regiāo estudada. O trabalho de investigação empírica abordou o desenvolvimento embrionário do turismo nas áreas rurais do Norte Velho do Paraná, Brasil, a partir das modalidades que estão surgindo, das experiências que seus pro- tagonistas estāo vivenciando e do perfil das pessoas que procuram o turismo rural como alternativa econômica e como visitantes. Por meio da necessária relação entre a abordagem teórica e empírica, há uma tentativa de contribuição para o conhecimento, entendimento e análise deste fenômeno cuja expansão é recente e, portanto, ainda pouco abordada pelos estudos geográficos.

\section{ET Espaço geográfico Guarani-mbya: significado, constituição e uso}

\author{
Maria Inês Ladeira
}

Este estudo concentra-se em aspectos espaciais, ambientais e sociais referenciais na composição do mundo Guarani-mbya e nos princípios éticos que definem o modo de vida desse grupo indigena. Busca apreender quais elementos materiais e simbólicos devem se reproduzir para a existência de seu mundo físico e cultural e como as regras de reciprocidade e de convivência mantêm a dinâmica de ocupação Guarani.

Considerando as expressōes e reflexōes dos índios Guarani-mbya sobre a terra (mundo) e o ambiente, este trabalho procura ampliar os limites do diálogo entre diferentes sistemas de conhecimentos e saberes.

A primeira parte (Nome) apresenta: questóes relativas à forma de abordagem do tema e ao contexto da pesquisa; quem sáo os pensadores Mbya; descrição e considerações sobre a situação fundiária e ambiental das terras Guarani; as classificaçóes vigentes na literatura etnográfica sobre o grupo indígena e como os Guarani se identificam e aos outros.

A segunda parte (Terra) contém abordagens sobre a ocupaçāo territorial Tupi-guarani; enfoques teóricos sobre território e espaço; conceitos jurídico-antropológicos sobre ocupação tradicional indígena; características do espaço geográfico Guarani-mbya e como eles substanciam o território; fundamentos míticos do mundo terrestre.

A terceira parte (Vida) discorre sobre aspectos éticos que fundam o modo de vida Guarani-mbya; os lugares e caminhos dos seres que povoam o mundo; como vivem e reproduzem, no tekoa (aldeia), a vida coletiva.

Esta tese é uma contribuição à compreensão das tensōes que se processam no interior de um grupo étnico em contato sistemático com a sociedade nacional e dos mecanismos encontrados - envolvendo tradição, memória e renovação - para reagirem às pressōes no mundo atual. Manter a dinâmica territorial tem sido a forma mais efetiva de exercer sua autonomia.

Palavras-chave: Guarani, dinâmica, reprodução, território, modo de vida, lugar.

\section{Geografia e turismo no paraíso das águas: o caso de Bonito}

Milton Augusto Pasquotto Mariani
Este estudo se refere ao fenômeno do turismo sobre o prisma da geografia, o que requer assumir o papel fundamental de dedicar à análise dos processos de (re)produção do espaço tu- 
rístico, sua organização e aproveitamento de suas potencialidades em benefício da população local e dos que nele buscam o lazer. A abordagem geográfica do tema proposto para o município de Bonito constituiu em de análise do espaço geográfico para as investigaçōes, sob a visão da geografia pragmática. Os resultados da pesquisa aqui apresentados procuram valorizar a realidade da atividade desenvolvida nas proximidades da Serra da Bodoquena, em Mato Grosso do Sul, que vem se caracterizando como um turismo em espaço rural, compatível com o interesse da crescente demanda sobre o território. O objetivo geral do presente trabalho é estudar o turismo, analisando, concomitantemente, a atividade turística como produto da sociedade de consumo e a questão ambiental, as políticas públicas e as açōes da iniciativa privada que incidem sobre o território de Bonito. Procurou-se entender o modo como se dá a apropriação de uma determinada parte do espaço geográfico pelo turismo, a qual depende da política pública de turismo que se leva a cabo no lugar. À política pública de turismo cabe o estabelecimento de metas e diretrizes que orien- tem o desenvolvimento socioespacial da atividade, no que tange à esfera pública e iniciativa privada. Como as políticas públicas, as açōes da iniciativa privada e a preocupação com a questão ambiental encontram-se no território de Bonito em fase de implementação, esta análise pautouse, sobretudo, na capacidade ordenadora dessas açōes, no que se refere ao território por elas abrangido. A valorização das políticas públicas, das ações da iniciativa privada e a preocupação com a questão ambiental basearam-se na preocupação de mostrar o quanto à idéia de desenvolvimento da atividade turística em Bonito, por meio do turismo e de seus agentes multiplicadores, vem sendo difundida de forma inadequada, para que as mesmas possam realmente se mobilizar para ordenar seus processos particulares de conquista da felicidade coletiva, náo apenas pela agregação de renda, mas sobretudo pela viabilização de estratégias de promoção da qualidade de vida em âmbito local.

Palavras-chave: Turismo, meio ambiente, políticas públicas, iniciativa privada, território.

\section{T A formação da memória territorial brasileira (1838 a 1860)}

\author{
Regina Celia C. Araújo
}

Esta tese pretende demonstrar que a formaçāo da memória nacional, cultivada sistematicamente pela historiografia nascente e pela literatura romântica nas primeiras décadas do século XIX, baseou-se, em grande medida, na exaltaçăo das virtualidades contidas no território. A invençāo de um passado nacional, ancorado em documentos e monumentos cuidadosamente selecionados, correspondeu à apropriação real e virtual da base territorial do império, cuja memória é reconstruída neste período pelas publicaçōes do Instituto Histórico e Geográfico e pelos "romances brasileiros" dos escritores românticos. Por meio do estudo dos momentos iniciais da historiografia e do pensamento geográfico no Brasil, esta tese procura demonstrar que estas duas disciplinas ocuparam papéis complementares, que não podem ser explicados em separado. Buscando no passado os signos de uma protonacionalidade e integrando em uma memória territorial imaginada como brasileira o espaço fragmentado produzido pelas colônias portuguesas da América, estes dois campos disciplinares em vias de sistematização forneceram os fundamentos indispensáveis à constituição da nação brasileira.

Palavras-chave: Formaçāo territorial, naçāo, Instituto Histórico e Geográfico Brasileiro, império brasileiro, Estado. 


\section{TT Análise ambiental em unidades de paisagens na Amazônia mato-grossense: \\ A importância do fator regional na conduçáo do processo}

\author{
Tereza Cristina C. de Souza Higa
}

Neste trabalho procurou-se fazer, sob a perspectiva do enfoque regional geográfico, a análise ambiental de parte da Amazônia matogrossense, tomando como referência de observação a unidade de paisagem e a produção de seu espaço no contexto regional. Assim, procederam-se o mapeamento da ação antrópica e cobertura da terra da área estudada no período compreendido entre 1978 e 1999, destacando-se o avanço da ocupaçáo agropecuária e dos desmatamentos generalizados e suas conseqüências ambientais, expressas, sobretudo, pela fragmentação das unidades de paisagens. Toda a situação vigente foi analisada sob o enfoque regional no bojo dos interesses nacionais, mega-regionais ou mesmo mundiais de caráter social, econômico e político que atuam sobre a produçăo do espaço local, vinculando-o com o espaço mundial.

Palavras-chave: Amazônia, paisagem, geografia regional, análise ambiental, análise regional.

\section{TI Planejamento governamental: a Sudeco no espaço mato-grossense. contexto, propósitos e contradiçóes}

\section{Silvana de Abreu}

O objetivo deste trabalho foi, principalmente, analisar as transformaçóes ocorridas no espaço mato-grossense, sob a égide do planejamento e intervenção da Sudeco. O sustentáculo teórico-discursivo para as elaboraçōes programáticas e para as açōes empreendidas foi o desenvolvimentismo e a racionalização. O espaço mato-grossense, até 1979, constituía-se no Estado de Mato Grosso, tendo consolidado, no processo de ocupação e intervenção promovido pela superintendência, diversidades e semeIhanças que foram identificadas e transformadas em argumentação científica e política de planejamento para a divisāo administrativa que resultou na criação dos estados de Mato Grosso do Sul e Mato Grosso. Os anos 80, para o oeste brasileiro e, principalmente, para o espaço mato-grossense (já dividido em MS e MT) consubstanciaram-se como um período de grandes transformaçōes socioespaciais. A Sudeco implementou o projeto de "venda" da regiāo sob sua jurisdição - a Nova Fronteira e a "Regiāo Solução" -, atrelado à idéia de industrialização das matérias-primas regionais produzidas - agroindústrias -, com vistas a exportar produtos semi-acabados e não apenas in natura. Os limites do modelo e a crise do planejamento $e$ intervençāo governamental tornaram-se agudas, nos anos 90, no interior do processo de enfraquecimento do Estado-Nação e do projeto desenvolvimentista. Trata-se agora, de promover um "novo padrāo de desenvolvimento" proposto no contexto de um limite possível de recursos e vinculado à problemática ambiental mundial que cria/alimenta uma indústria ambiental e o desenvolvimento sustentável, como um novo discurso ideológico, retomando alguns conceitos $e$ intençōes, como disparidades regionais, desenvolvimento e fomento à iniciativa privada.

Palavras-chave: Desenvolvimentismo, superintendência de desenvolvimento do CentroOeste - Sudeco, Mato Grosso e Mato Grosso do Sul, planejamento governamental. 


\section{Dissertaçōes de Mestrado}

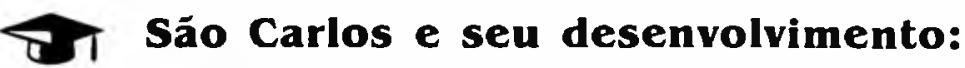 contradiçóes urbanas de um pólo tecnológico}

\section{Alessandro Dozena}

O crescimento urbano em São Carlos tem sido acompanhado por problemas resultantes, principalmente, da ausência de uma política urbana claramente definida. Conseqüentemente, evidencia-se uma desigual distribuiçāo da infraestrutura e a emergência de bolsões de ocupação nas regiōes mais periféricas da cidade, mar- cadas pela diferença da qualidade de vida em relaçāo aos habitantes das áreas mais nobres. A partir de elementos que caracterizam a sua transformação urbana, dissertamos sobre a expansão da malha urbana: a segregação resultante desta expansão; a deficiente urbanização; a verticalizaçāo; os vazios urbanos; a intensa transformação da área central; os problemas ambientais; a incongruência entre a ocupação do solo urbano e a qualidade de vida da população local; a prioridade do econômico sobre o social, e a inserção da cidade em um contexto de globalizaçāo e de "guerra fiscal"

\section{Ti Estudo da morfologia do relevo, materiais e processos em uma estrutura de relevo cristalina: "Mestre Álvaro" municipio Serra, ES, Brasil.}

\section{Ana Christina Wigneron Gimenes.}

Relativamente à definição de sistema geomórfico, fundamentado na proposição conceitual de Ab'Saber (1969) e de acordo com a interpretação apresentada por CARSON e KIRKBY (1972), é ele composto pela morfologia do relevo, estrutura e processos, concebido como uma unidade dialética dinâmica e descontínua.

Aplicados os princípios do método de abordagem sistêmica, ênfase é dada à investigação do sistema geomórfico nos limites de um compartimento geomorfológico montanhoso costeiro de formato semicircular em planta, "Mestre Álvaro" (Serra, ES, Brasil), onde a morfologia do relevo, os materiais superficiais rochosos e os inconsolidados (elúvios, colúvios, alúvios), os fluxos hídricos e erosivos atuais são considerados.
O objetivo é reconhecer o arranjo espacial desse sistema geomórfico, a começar pela identificação das formas $e$, averiguada sua distribuição, inferir sobre seu desenvolvimento.

As diferenças demonstradas pela morfologia de relevo em diferentes setores topomorfológicos e faces de orientação são investigadas e delas um mapeamento sintético e normativo de conteúdo geomorfológico é resultante.

Os processos geomórficos apresentam uma nítida relaçāo entre suas disposiçōes e os condicionantes lito-estruturais, morfológicos, biológicos, pedológicos e antrópicos que os determinam. Além disso, a expressão espacial dos fluxos hídricos, que são o principal agente modelador das formas de relevo, é importante para essa consideração.

As evidências nas morfologias, indicam a existência de etapas de desenvolvimento do relevo, seqüenciais e não lineares.

Palavras-chave: Morfologia, relevo, materiais, processos, erosão, mapeamento, morfogênese. 


\section{Tr Territórios do \\ patrimônio, tombamentos e participaçáo social na cidade de São Paulo}

\author{
Cíntia N. Rodrigues
}

A partir da análise das mobilizações sociais em favor de tombamentos na cidade de Sáo Paulo, a presente pesquisa se atém à questão da diversidade de usos e apropriaçōes do patrimônio e do território urbano.
Apontando para os limites e possibilidades que cercam essas mobilizaçōes sociais, nossa análise se desenvolve a partir de quatro perspectivas: a construçāo do patrimônio como direito social; as políticas governamentais de preservaçāo, de urbanismo e planejamento: a defesa do patrimônio relacionada com a construção e afirmação da cidadania; e as representações da cidade e do espaço urbano evidenciadas nas lutas pela preservaçāo de territórios do patrimônio.

Palavras-chave: Patrimônio, território, tombamento, mobilizaçōes sociais, preservação.

\section{Tr Planejamento e gestão territorial: o Municipio de Atibaia}

Dario Jose Machado Ribeiro

Esta Dissertação de Mestrado foi desenvolvida com o objetivo de analisar as políticas públicas adotadas pelo município de Atibaia, principalmente nos últimos vinte anos, e conhecer quais foram os resultados espaciais decorrentes

Partindo do entendimento de que o planejamento é um conceito a ser praticado pelas administraçōes municipais, ela apresenta, no seu final, uma proposta de planejamento para o município de Atibaia. Esta proposta leva em consideração, não apenas as características vocacionais do município, mas também incorpora os novos conceitos e paradigmas do planejamento e da gestão urbana.

O município de Atibaia está localizado às margens da rodovia Fernáo Dias, a cerca de $60 \mathrm{~km}$ da capital do estado de São Paulo e sofre influência crescente da metrópole. Com população de 111.000 habitantes, clima ameno, paisagem exuberante e localização privilegiada, está assistindo passivamente ao crescimento de sua população a um ritmo de cerca de $4 \%$ ao ano, o que coloca em risco as suas melhores qualidades.

Temos a expectativa de que, com este estudo e o entendimento de que é necessário planejar, o município de Atibaia e a sua população possam ter um desenvolvimento espacial mais harmônico e socialmente mais justo.

\section{TI A moradia popular chegou à Serra da Cantareira}

Fabio César Moreira Manente

O desmembramento da terra destinado à população pobre, freqüentemente é realizado à margem da legalidade urbanística e fundiária. Nessa produção atuam o Estado, através dos conjuntos habitacionais náo regularizados, e os loteadores, por loteamentos irregulares ou clan- destinos. Este trabalho procura relacionar a moradia com a propriedade privada da terra, utilizando como exemplo um dos sítios que ainda compunham os arredores da cidade de São Paulo no início do século XX, para verificar como a propriedade territorial foi sendo desmembrada. O descompasso entre o tempo da urbanização e o tempo da legislação, bem como entre o tempo de vida do homem e o tempo necessário para se obter recurso financeiro para adquirir a moradia, está registrado no desenho da cidade. 


\section{Tr Território e cultura. Uma problemática para a política dos incentivos fiscais no marketing cultural}

\author{
Julia Santos Cossermelli de Andrade
}

A atual Política Cultural brasileira está pautada nas chamadas Leis de Incentivos Fiscais. Essas leis permitem que os agentes privados - empresas - deduzam parte de seu imposto devido ao governo e invistam em um produto cultural.

Essas empresas associam sua imagem à imagem de uma determinada obra de arte ou evento cultural, e desta forma praticam o chamado marketing cultural.
Entretanto, essas recentes leis não estão conseguindo evitar uma concentração ainda mais intensa e perversa dos recursos na Região Sudeste, em especial no Eixo Rio Sāo Paulo. Esses recursos públicos também estão sendo utilizados, muitas vezes, para atividades puramente comerciais e elitizadas. Esta pesquisa apresenta algumas distorçōes que devem ser modificadas na legislaçāo para que se possa garantir um país com diversidade cultural e acesso aos bens públicos por toda a população, independentemente onde esta se encontre. O acesso à cultura é um direito inalienável do cidadão.

Palavras-chave: Politicas culturais, leis de Incentivos Fiscais, marketing cultural, cidadania cultural, lei Rouanet e lei do Audiovisual, cinema brasileiro.

\section{Tr Gestão municipal e conservação da natureza: a bacia hidrográfica do Ribeirão das Anhumas - Campinas/SP}

\section{Marisa Teresinha Mamede Frischenbruder}

Este trabalho situa-se no campo das discussōes sobre proposiçōes e práticas de planejamento e gestāo municipal brasileiras, analisando-se particularmente questōes relativas a condiçōes ambientais e conservação da natureza. Tem como centro da análise o processo de implementação de política ambiental, na sua dimensão territorial, realizado no município de Campinas/SP no período 1993/96 e, particularmente, em 1996, quando grande parte da concepção de política de ordenamento municipal tinha já sido concretizada em leis, regulamentos e rotinas de trabalho no Departamento de Meio Ambiente, da Secretaria Municipal de Planejamento e Meio Ambiente, representando o conjunto mais acabado dessa concepção de política. O estudo foi realizado para uma sub-bacia hidrográfica do município, a do Ribeirão das
Anhumas, contribuinte do rio Atibaia, situada na porção Centro - Norte/Noroeste de Campinas. Neste trabalho, foi dada ênfase aos aspectos relacionados à conservação da natureza em áreas intensamente ocupadas - urbanas e rurais - e consideradas algumas estratégias que podem ser desenvolvidas pelo Poder Público Municipal. Para essa análise, além do exame dos documentos relativos à política e do traçado do percurso realizado entre as concepçōes e a sua concretizaçāo em práticas, técnicas e açōes para implementação, foi construido um modelo cartográfico simplificado do território, procurando caracterizar a paisagem sob gestāo pública e aspectos importantes da evoluçāo histórica de ocupaçāo da regiāo. Foram identificadas analogias entre os modelos trabalhados e processos de evolução de modelos, quando estes são utilizados como instrumentos de conhecimento $e$ ação sobre a realidade e modificados, conforme esse processo evolui.

Palavras-chave: Gestāo ambiental, conservação da natureza em áreas urbanas, técnicas cartográficas, unidades de paisagem, biótopos. 


\section{Estudo da queimada da cana-de- açúcar em Iracemápolis, SP: espacialidade, percepção e cognição ambientais}

\author{
Renata Barrocas
}

Este trabalho chama a atenção para os efeitos da queimada da cana-de-açúcar na cidade de Iracemápolis, SP.

Procurou-se trabalhar a espacialidade, a percepçāo e a cogniçāo ambientais por meio de pesquisa de campo, realizada com os moradores, durante a safra (1998) e a entressafra (1999) da cana-de-açúcar. Com o objetivo de apresentar a manifestação da fuligem na cidade durante a safra de 2000 e o final da safra de 1999 , placas adesivas ficaram expostas durante trinta dias em cada período.

Iracemápolis, localizada no interior paulista, recebe todos os anos, na safra, a fuligem oriunda da queimada da cana. Nesse período, a cidade muda de cenário. Apesar da poluição e da sujeira, há emprego na colheita e na Usina Iracema, considerada pelos moradores o símbolo do progresso municipal.

Palavras-chave: Iracemápolis, queimada da cana-de-açúcar, espacialidade, percepção e cogniçāo.

\section{Residuos sólidos: práticas e conceitos. Um estudo a partir da experiência de Londrina/PR}

\section{Wladimir Cesar Fuscaldo}

Este trabalho procura desvendar elementos e conceitos que contribuam para a compreensão dos problemas relacionados ao gerenciamento dos resíduos sólidos, particularmente dos resíduos sólidos domiciliares, estudando o caso do Município de Londrina - Paraná. A discussão dos conceitos aborda vários tópicos relacionados: resíduo sólido, lixo, coleta domiciliar, coleta seletiva, reciclagem, compostagem, usina de triagem e compostagem, incineração, pirólise, aterros comuns ou lixōes, aterros controlados, aterros sanitários, aterros energéticos e chorume ou sumeiro. A pesquisa empírica partiu da experiência de trabalho realizada, como geógrafo, na Autarquia Municipal do Ambiente, em Londrina, e procura mostrar sucin- tamente as condiçōes da disposição final dos resíduos sólidos urbanos no lixão e as tentativas realizadas para a redução dos volumes de resíduos sólidos, representadas pelos projetos de coleta seletiva e de compostagem elaborados a partir do ano de 1991, e de alguns outros projetos precursores, incluindo projetos realizados em outros municípios brasileiros. Os programas de coleta seletiva são analisados nos resultados apresentados e nas suas potencialidades para a reduçāo dos volumes de resíduos sólidos a serem aterrados. São abordadas também a reciclagem e a compostagem, com uma breve descrição da Usina de Triagem e Compostagem adquirida pela prefeitura municipal no ano de 1996 e até o presente momento náo instalada, o que encaminha para as políticas públicas. Assim, o último capítulo vai abordar, resumidamente, as políticas para o setor, necessárias para o equacionamento da questão, cada vez mais premente, dos resíduos sólidos.

\section{Identificação de Unidades Ambientais no Municipio de Atibaia/SP}

Vanderlei Sergio da Silva
Este projeto apresenta uma caracterização ambiental do Município de Atibaia elaborado segundo critérios e procedimentos voltados à aplicação no planejamento ambiental do município. 
Atibaia é uma estância turística e hidromineral situada em uma posição privilegiada do Estado, na porção intermediária entre os grandes centros de São Paulo, Campinas, São José dos Campos e Sul do Estado de Minas Gerais.

Seus cerca de 101.000 habitantes distribuem-se em $491 \mathrm{~km}^{2}$ de área territorial, ocupando núcleos urbanos com grande diversidade so- cioeconômica e um setor rural de relevada importância no contexto regional e estadual.

O que mais caracteriza Atibaia, no entanto, é a sua paisagem de rara beleza cênica, o clima aprazível e ameno e o conjunto integrado de componentes ambientais que emprestam ao Município sua inegável vocação para o turismo.

\section{Tr 0 espaço do dengue: reflexōes sobre a análise espacial do dengue: o espaço}

\section{Joāo Evangelista de Souza Lima Neto}

Este trabalho é um estudo da produção sobre o dengue realizada no estado de São Paulo, no período de 1993 a 1999.

Inicialmente foi desenvolvida uma reflexão sobre a Geografia Médica, seus principais autores e linhas de análise, bem como sua relação com a epidermologia.

Foram analisadas dissertações de mestrado e teses de doutoramento, defendidas na
Faculdade de Saúde Pública e Faculdade de Medicina de Ribeirão Preto, da Universidade de São Paulo e na Faculdade de Ciências Médicas da Universidade de Campinas.

Esses trabalhos foram analisados em relação aos fatores que são apresentados como determinantes na ocorrência e distribuição do dengue e/ou Aedes aegypti, tais como temperatura, pluviosidade, densidade demográfica, coleta de lixo, abastecimento de água, sistema viário e padróes de consumo.

Observaram-se, também, quais os conceitos de ambiente encontrados nestes trabalhos, bem como as propostas de combate ao dengue $\mathrm{e}$ ao Aedes aegypti apresentados.

\section{RT Representaçóes da paisagem do Parque Nacional da Serra da Canastra - MG: o olhar do viajante, da população local e do geógrafo}

\section{Gelze Serrat de Souza Campos Rodrigues}

A partir dos conceitos de paisagem e representaçāo procurou-se analisar as representaçōes espaciais dos turistas e da populaçāo local do Parque Nacional da Serra da Canastra - MG, a fim de se compreender quais fatores intervêm no processo de percepção ambiental dos dois grupos, bem como de que forma se engendram alguns de seus valores e atitudes condizentes à paisagem do Parque.
Após o levantamento de diversas concepções de paisagem, é proposta a adoção da acepção de Bailly que aglutina o conjunto de elementos constituintes do ambiente às formas de vê-lo, ou seja, às representaçōes que deles fazemos, abrangendo aspectos sociais, culturais e individuais. Tomando as representaçōes do espaço um dos referenciais teóricos, investigou-se as leituras dos indivíduos perante a(s) paisagem(s) do Parque Nacional da Serra da Canastra, obtidas em trabalho de campo por meio de entrevistas e mapas mentais.

Com o encaminhamento das análises, pondera-se sobre os efeitos do discurso veiculado pela mídia e trade turístico, do processo de 
sacralizaçāo do Parque Nacional e das histórias pessoais sobre as representaçōes dos dois grupos, assim como se faz uma reflexão sobre as contribuições que os estudos acerca deste tema podem trazer para a compreensão mais refinada da paisagem.

\section{Tr Territórios e o movimento integralista: uma contribuiçáo ao estudo das ideologias geográficas no pensamento autoritário brasileiro das décadas de 1920 e 1930}

\section{Paulo Roberto de Albuquerque Mourão}

Este trabalho tem o objetivo de analisar as ideologias geográficas (os discursos inseridos direta ou indiretamente na articulação entre pensamento geográfico e a esfera político-cultural de uma sociedade) no pensamento político autoritário brasileiro das décadas de 1920 a 1930 . O principal objeto de estudo - o movimento integralista brasileiro (1932 a 1937) - é relacionado a outras tendências autoritárias de direita (antiliberais, nacionalistas e anti-socialistas) como a jeunesse dorée (os católicos da revista A Ordem Alceu Amoroso Lima, Octávio de Faria - e Affonso Arinos de Mello Franco) e os geopolíticos (Everardo Bauckheuser, Mário Travassos e Elysio de Carvalho). Os pensadores autoritários de maior en- vergadura do período (aqueles ligados ao Estado Novo) não fazem parte desta pesquisa, por terem sido já bastante estudados, mas percorrem - pela sua importância - grande parte deste texto. A identidade nacional ligada à formação territorial do Brasil, a questão da descentralização/centralizaçāo político-administrativa, o debate entre a alternativa econômica agrária e a industrial, a questão da ocupação plena do território nacional, $\mathrm{e}$ as formas de ação e planejamento do Estado são temas de nítido recorte espacial que fizeram parte das propostas de escritores políticos e intelectuais em um período que marca o impasse da velha economia de arquipélago e do liberalismo formal da Primeira República no vazio político que se segue à Revolução de 1930. Muitos destes temas seriam assimilados - com certos reajustes - à política oficial do Estado Novo (1937 a 1945) e se estenderiam no discurso político - à esquerda e à direta - por décadas.

Palavras-chave: Movimento integralista, pensamento político autoritário no Brasil, ideologias geográficas, território, Estado.

\section{Tr Os loteamentos de traçado orgânico realizados no Município de São Paulo na primeira metade do século $\mathrm{XX}$}

\section{Célia Seri Kawai}

Este trabalho trata dos loteamentos com traçado orgânico, especialmente os de caráter mais popular, realizados na primeira metade do século XX, no município de São Paulo. As origens remotas desse tipo de traçado podem ser situadas nas cidades-jardins inglesas e nos subúrbios- jardins americanos. Estes modelos, que lhes serviram de inspiraçāo, foram transformados na sua transposição para a realidade brasileira e paulistana, assumindo primeiramente a forma de bairros-jardins destinados às elites. Mostrou-se como estes bairros foram acolhidos no contexto socioeconômico-cultural da época e como foram rapidamente imitados e disseminados na forma de loteamentos populares. Nestes observaramse diferenças qualitativas consideráveis, variando entre a excepcional qualidade de projeto de alguns $e$ as versōes simplificadoras da maioria. 
Investigou-se quem eram os promotores e projetistas destes empreendimentos, constatando-se o importante papel exercido pelas escolas de engenharia na formaçáo dos técnicos que atuaram no projeto e na aprovaçáo deles. Identificaram-se os engenheiros que mais se destacaram na produ- ção deste tipo de loteamento, focalizando o engenheiro Jorge de Macedo Vieira como um estudo de caso, comentando suas obras em São Paulo.

Palavras-chave: Urbanismo, cidade-jardim, loteamentos, paisagem urbana e engenheiros urbanistas.

\section{T/ 0 Bairro Reforma Agrária e o processo de territorialização camponesa}

Larissa Mies Bombardi

Este trabalho trata do estudo de um Bairro Rural que se originou a partir de um projeto de assentamento realizado pelo Estado, na década de 1960, em São Paulo.

Procurou-se compreender o contexto histórico da aprovação da Lei de Revisão Agrária a partir da qual foi originado esse assentamento.

A análise deste projeto de reforma agrária envolveu a reconstrução da trajetória das famílias camponesas antes de adquirirem a terra por meio desta reforma agrária e, sobretudo, após tê-la adquirido.
Como o título do trabalho procura indicar, os camponeses do Bairro Reforma Agrária têm construído uma unidade territorial - diferente do território apropriado de forma tipicamente capitalista - ao longo dos mais de trinta anos desde que foram assentados, que é o resultado da inter-relação de vários elementos: o trabalho camponês, as características do meio natural, a relação dos camponeses entre si e a relação destes com o mercado.

Esta nova unidade territorial forjada pelo trabalho camponês, o Bairro Rural surge como uma fração do território mais justa do ponto de vista social e aponta, a partir de sua análise, para a necessidade da realizaçăo de uma reforma agrária ampla no país.

\section{TI 0 meio técnico-científico- informacional brasileiro: a publicidade como um vetor das modernizaçóes}

Lídia Antongiovanni

O presente trabalho busca discutir o papel da publicidade no mundo contemporâneo, tratando-a como elemento constitutivo do meio técnico-científico-informacional brasileiro. Procuramos mostrar a Importância que esta atividade toma no período da globalização e como - Brasil se insere nesta nova divisão internacional do trabalho, ressaltando que os impactos da globalizaçāo na formação socioespacial brasileira reforçam as desigualdades historicamente construídas.
O croqui cartográfico no ensino da Geografia: ensaio metodológico
Neste trabalho, procuramos discutir os croquis cartográficos como um recurso metodológico no ensino de Geografia. Encontramos nas teorias de Comunicaçāo Cartográfica e de 
Visualizaçāo Geográfica um caminho para o entendimento da eficácia dos croquis cartográficos como método didático. Em complemento, a análise da linguagem gráfica nos forneceu um instrumental para abordar a questão da construçāo das representaçóes.

Estas análises nos proporcionaram uma maior compreensão da maneira como os individuos extraem informações e constroem os mapas.

A partir das bases acima, procuramos desenvolver nossa pesquisa, trabalhando com alunos da $5^{a}$ série do ensino fundamental, na faixa etária de 11 a 12 anos, elaborando atividades nas quais o croqui cartográfico é utilizado como um método de ensino da Geografia.

\section{Análise da fragilidade ambiental relevo e solo, com aplicação de três modelos alternativos nas altas bacias do rio laguari-Mirim, Ribeiráo do Quartel e Ribeirão da Prata}

\section{Christiane Sporl}

Este trabalho apresenta uma comparação de três modelos metodológicos aplicados aos estudos da fragilidade ambiental. A aplicação destes modelos resultou na confecção de três mapeamentos diferenciados de fragilidade, os quais foram analisados e comparados entre si.

Dos três modelos metodológicos aplicados, dois foram propostos por ROSS (1994), um com apoio nos índices de Dissecação do Relevo, e o outro nas Classes de Declividade. O terceiro modelo foi proposto pelo INPE (1996) baseado nas Unidades Territoriais Básicas - UTB'S.

Os três modelos de análise da Fragilidade Ambiental propostos partem do mesmo princípio: as Unidades Ecodinâmicas preconizadas por TRICART (1977) para delimitar áreas no contexto dos diagnósticos ambientais. As áreas são caracterizadas por diversos atributos: rochas, relevo, solo, cobertura vegetal/uso da terra e pluviosidade. No entanto, estes modelos apresentam diferenças na operacionalização dos métodos, e também, nas variáveis analisadas. Destas divergências resultam três mapeamentos diferenciados.

Apesar dos diferentes resultados apresentados pelos três modelos de análise da Fragilidade, seus objetivos são os mesmos, servir como subsídio ao planejamento estratégico-ambiental. Os mapeamentos das Fragilidades Ambientais identificam e analisam os ambientes em função de seus diferentes niveis de fragilidade. Por meio destes documentos torna-se possivel apontar as áreas onde os graus de fragilidade são mais baixos, favorecendo, então, determinados tipos de inserção; e áreas mais frágeis onde sāo necessárias açōes tecnicamente mais adequadas a essas condiçōes.

Palavras-chave: Planejamento, zoneamento ecológico, fragilidade ambiental, metodologias, modelos.

\section{Tr Um estudo sobre o uso da água na bacia do rio Mogi Guaçu: políticas, conflitos e gestáo}

\section{Carlos Alberto Pinheiro}

O objetivo do presente trabalho é analisar os usos dos recursos hídricos e os conflitos socioeconômicos regionais que interferem nos índices de qualidade e quantidade de água dos mananciais superficial e stibtei-i-itico da porção paulista da bacia hidrográfica do rio Mogi Guaçu,

Este estudo também abordou as principais açōes político-institucionais criadas com o intuito de solucionar as questões ambientais e hídricas nessa unidade hidrográfica. 
A primeira ação investigada foi a do comitê da bacia hidrográfica, criado em 1996. órgáo colegiado responsável pelas atividades de gestão da política estadual do setor e pela aplicaçáo dos estudos, planejamento e obras.

A segunda foi o Estudo do Macrozoneamento dos Rios Mogi Guaçu/Médio Grande e Pardo, um amplo levantamento socioambiental cuja finalidade é a de orientar um tipo mais harmônico de desenvolvimento socioeconômico destas regiōes, que contemple a preservação e o uso racional do seu patrimônio ambiental e hídrico.

A terceira foi o Consórcio intermunicipal da Bacia do Rio Jaguari-Mirim, entidade que reúne municípios paulistas e mineiros entrecortados por este afluente do rio Mogi Guaçu. Ele foi criado com o intuito de solucionar os problemas ambientais provocados pela mineração de areia existente neste manancial.
Cabe destacar que estas duas últimas experiências surgiram da imobilização da vontade, da comunidade regional, de agentes públicos e de políticos que constataram diversos problemas sócio-ambientais que começavam a comprometer a disponibilidade e a integridade dos corpos hídricos regionais.

A par do objetivo precípuo desta dissertação, pretende apresentar uma contribuiçāo, talvez modesta, porém de reflexão e aplicação que se acredita procedente, qual seja, demonstrar que para a garantia atual e futura da água destinada ao consumo humano urge, nāo só esforços decorrentes do planejamento em si, investimentos apoiados em planos e obras de engenharia, mas também a concorrência relaçōes sociotécnicas que privilegiem os usos múltiplos e racionais dos recursos hídricos dessa bacia. 